\title{
Endoscopy in the management of a rudimentary non-communicating functional horn
}

\author{
Nitin H. Shah, Aditi V. Joshi*, Sunita Mourya
}

Department of Obstetrics and Gynecology, Vardann Multi speciality Hospital, Mumbai, Maharashtra, India

Received: 14 December 2018

Accepted: 11 January 2019

\section{*Correspondence:}

Dr. Aditi V. Joshi,

E-mail:avj111@gmail.com

Copyright: (C) the author(s), publisher and licensee Medip Academy. This is an open-access article distributed under the terms of the Creative Commons Attribution Non-Commercial License, which permits unrestricted non-commercial use, distribution, and reproduction in any medium, provided the original work is properly cited.

\begin{abstract}
Mullerian anomalies are developmental malformations of the female reproductive tract, often diagnosed late. They are classified into numerous types like a septate uterus, bicornuate or unicornuate uterus etc. A rudimentary noncommunicating functional horn is a rare variant of a unicornuate uterus. It may present with a wide spectrum of symptoms like severe dysmenorrhea, infertility, lump in abdomen or rarely maybe diagnosed with a ruptured ectopic in the horn. The diagnosis of this entity is a difficult and challenging. Authors present a case of a young adolescent diagnosed with this Mullerian anomaly, the role of hysteroscopy in confirmation of diagnosis and the management of the patient by laparoscopy successfully. The patient was completely relieved of her symptoms post-surgery.
\end{abstract}

Keywords: Hysteroscopy, Laparoscopy, Rudimentary noncommunicating functional horn

\section{INTRODUCTION}

Mullerian anomalies occur due to the arrest in various stages of development and fusion of the two Mullerian ducts, which are responsible for the development of the female reproductive tract. A unicornuate uterus is one of the rarest types of malformation in this spectrum. They comprise $0.4-1 \%$ of all Mullerian anomalies. ${ }^{1}$ Furthermore, a noncommunicating functional rudimentary horn is the least common subtype encountered and can pose great difficulties in the reproductive life of the woman.

The identification of Mullerian anomalies in young adolescent age group is important to warrant an optimal treatment. $^{2}$ Often imaging modalities like ultrasound, MRI can aid in the diagnosis. With advances in ultrasound imaging, even 3D ultrasound can provide a diagnostic accuracy as good as an MRI with experienced sonologist. ${ }^{3}$ Often resection of the non-communicating horn is necessary to avoid future complications. ${ }^{4}$

\section{CASE REPORT}

A 13-year-old adolescent presented with complaints of recurrent episodes of abdominal pain for 9 months and amenorrhea for one year. There were no other associated significant complaints. She had attained her menarche at the age of 12 years, however she had menstruated only for a single cycle. Her secondary sexual characteristics were well developed. On examination, body mass index was $19.2 \mathrm{~kg} / \mathrm{m}^{2}$, vital parameters were normal. On systemic examination, no abnormality was detected. On per abdomen examination, abdomen was soft. Local genital examination was normal. She was unwilling for a per rectal examination.

An ultrasonography was advised which was suggestive of a right sided endometriotic cyst of around $5 \mathrm{~cm}$ with a differential diagnosis of bicornuate uterus, for better tissue delineation, magnetic resonance imaging (MRI) was advised. Interestingly, her MRI was suggestive of a unicornuate uterus with a possibility of rudimentary right 
horn that was non-communicating comprising of a hemorrhagic collection in the horn and right sided hematosalphinx (Figure 1).

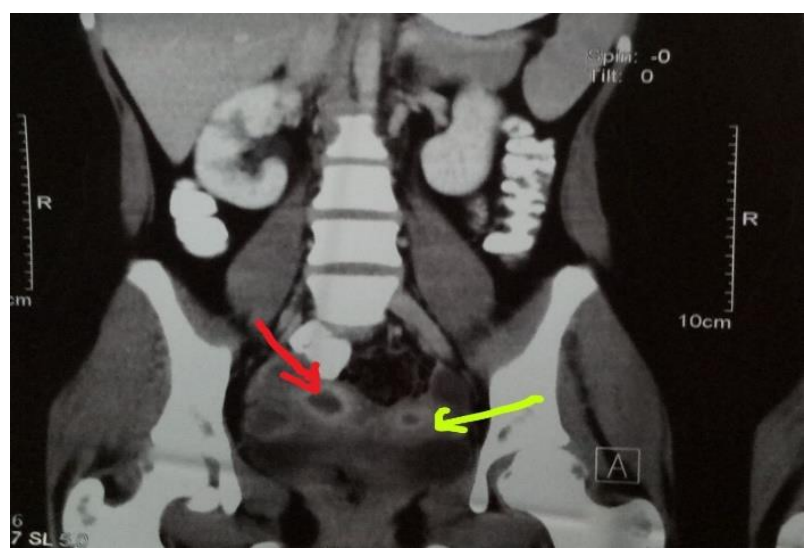

Red arrow depicts possibility of a rudimentary horn on right side; yellow arrow points to normal cavity.

Figure 1: MRI plate suggestive of a unicornuate uterus.

After counselling, she was posted for a laparoscopy. Authors also counselled regarding the need to perform a vaginoscopy and hysteroscopy to detect any other associated anomalies.

Authors began with the laparoscopy first, three abdominal ports were inserted, one $10 \mathrm{~mm}$ supraumbilical primary port and two $5 \mathrm{~mm}$ left accessory ports. On laparoscopy, the uterus appeared to be bicornuate. The ovaries were normal. Right side ovary showed small endometriotic cyst while the fallopian tube appeared engorged (Figure 2).

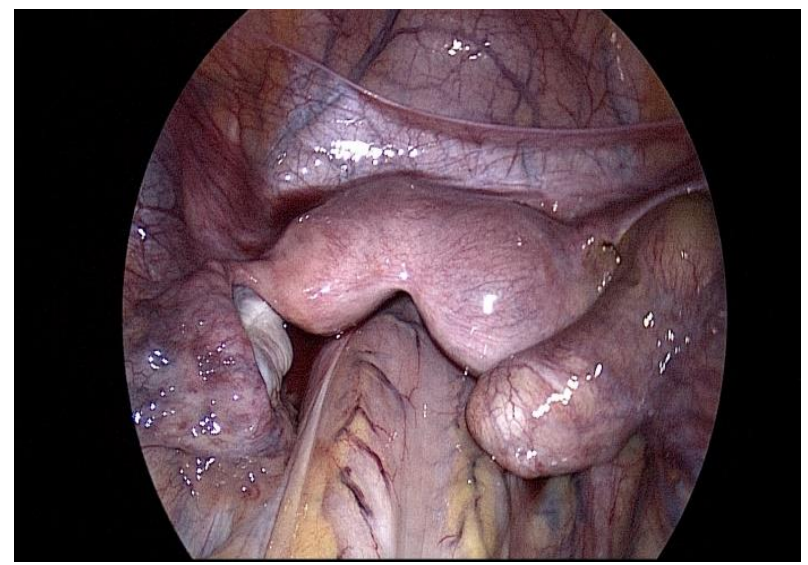

Figure 2: Initial appearance of bicornuate uterus with right sided hematosalphinx on laparoscopy.

A vaginoscopy and hysteroscopy was then performed to inspect the vagina, cervix and uterine cavity and detect any anatomical defects. On hysteroscopy, a tubular uterine cavity was noted with a single ostium visible on the left side (Figure 3).

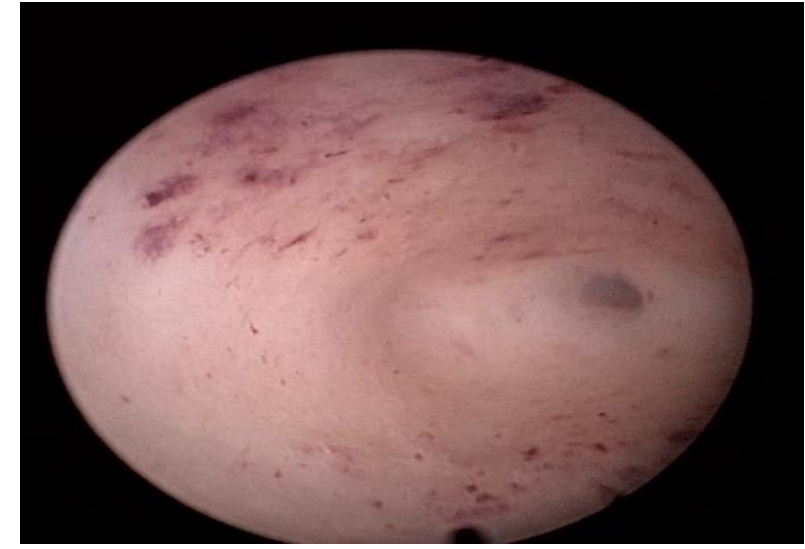

Figure 3: Image seen on hysteroscopy revealed a single cavity.

This was suggestive of a diagnosis of unicornuate uterus with a right side noncommunicating rudimentary functional horn (Figure 4).

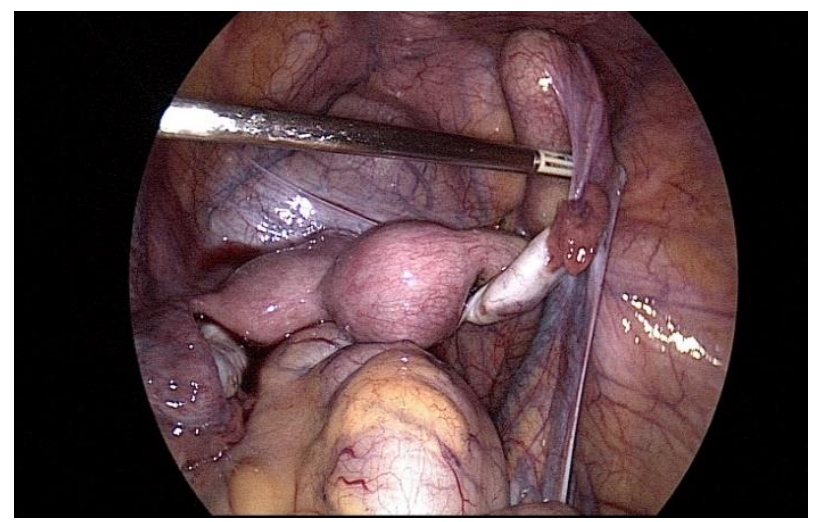

Figure 4: Image post hysteroscopic confirmation of a unicornuate uterus; the image depicts the right sided non-communicating functional rudimentary horn.

The right-side fallopian tube and ovary were attached to the rudimentary horn. The horn along with the fallopian tube were excised with the help of bipolar diathermy and harmonic (Figure 5).

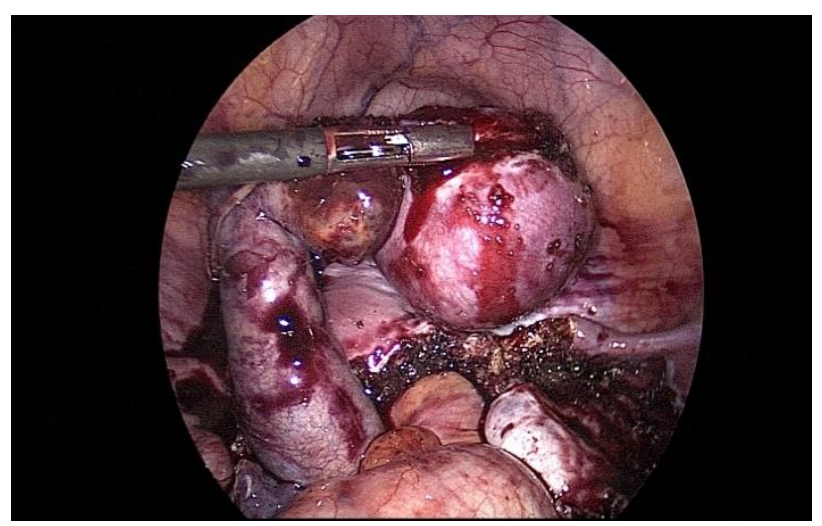

Figure 5: Excision of the rudimentary horn and right hematosalphinx. 
Cut section confirmed presence of hematometra and hematosalphinx. Small endometriotic cyst over the right ovary was drained and raw area fulgurated (Figure 6).

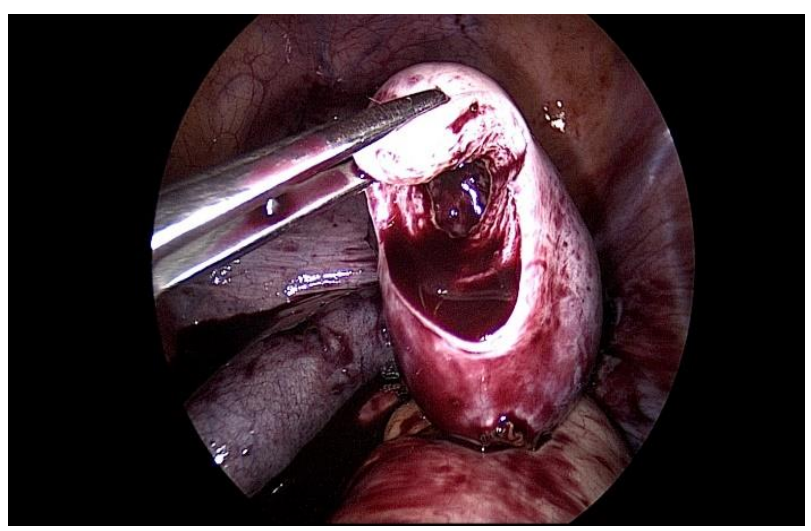

Figure 6: Drainage of the small endometriotic cyst.

Hemostasis was confirmed (Figure 7) and trocars were removed. Her postoperative course was uneventful. She was discharged on day 2 post surgery. On routine follow up after a month, she was completely relieved of her symptoms.

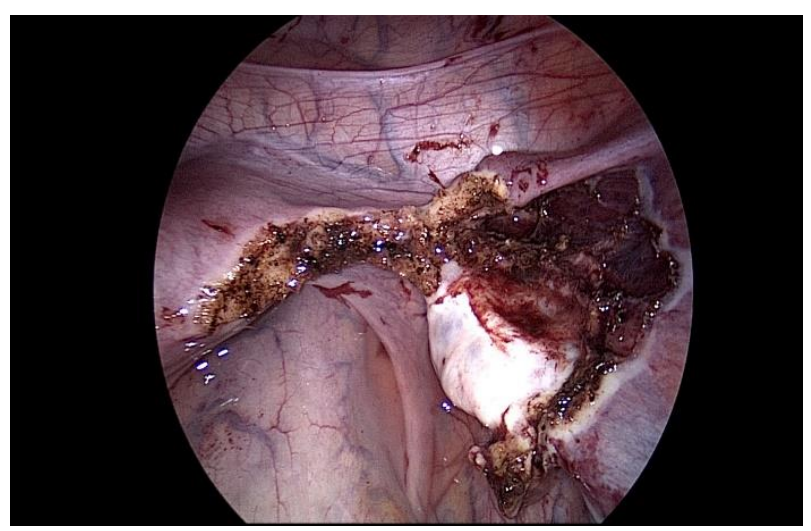

Figure 7: Final view after excision of the rudimentary horn and right hematosalphinx.

\section{DISCUSSION}

Mullerian anomalies are classified into various subtypes. The American Fertility Society classifies unicornuate uterus into type II uterine malformations with further subdivisions depending upon presence of a rudimentary horn and a functional endometrium within. ${ }^{5}$ The newer classification according to ESHRE-ESGE classifies unicornuate uterus as U4 (hemi-uterus) subtype. ${ }^{6}$ The exact incidence of unicornuate uterus is difficult to determine owing to a large population being asymptomatic. However, numerous studies have cited the incidence to range from $2-10 \% .^{7}$ Most patients are asymptomatic and incidentally diagnosed. It may be diagnosed when the patient presents with severe dysmenorrhea due to complications like hematometra and hematosalphinx. Rarely, an incidental discovery of the ruptured horn occurs due to an undiagnosed ectopic pregnancy. Hence, a surgical intervention is warranted upon its detection even in cases where the horn is noncommunicating, since a functional endometrium can lead to an ectopic pregnancy. The excision of the noncommunicating horn in adolescent population can relieve the patient of her dysmenorrhea and prevent severe complications of endometriosis.

The detection of a rudimentary horn with a functional cavity is often delayed. However, in young adolescent girls, timely diagnosis and excision can help prevent possible development of endometriosis in the future. The mode of surgery adopted depends upon the desire of the patient and the surgical expertise of the surgeon. Laparoscopy is the gold standard for management as it warrants a diagnostic and therapeutic treatment in the same setting. ${ }^{8}$ An asymptomatic rudimentary horn must also be excised at the time of diagnosis to avoid future complications.

The role of imaging modalities in pre-operative evaluation has gained a momentum and can aid in better planning for surgery. MRI is considered the imaging modality of choice considering better tissue delineation, however with recent advances in ultrasound, 3D ultrasonography can achieve similar diagnostic potential. ${ }^{9}$ Vaginoscopy and Hysteroscopy are upcoming modalities for diagnosis and can serve as a useful adjunct to confirm the diagnosis. Vaginoscopy and hysteroscopy can be performed as office procedures owing to the development of sheaths with smaller diameters, which preclude the need for cervical dilatation. ${ }^{10}$

Thus, hysteroscopy due to direct visualization of the uterine cavity enables us to arrive at a conclusive diagnosis. Also, laparoscopy being a keyhole surgery is beneficial for faster recovery of the patient.

\section{CONCLUSION}

In the era of minimal access surgery, laparoscopy is first choice for treatment and provides innumerable benefits over laparotomy. A precise evaluation and a proficient laparoscopic surgeon can provide the patient with profound pain relief and a better quality of life. Hence, every clinician must be vigilant about diagnosing these anomalies in the young adolescent.

Funding: No funding sources

Conflict of interest: None declared

Ethical approval: Not required

\section{REFERENCES}

1. Byrne J, Nussbaum-Blask A, Taylor WS. Prevalence of mullerian duct anamolies detected at USG. Am J Med Genet. 2000;94(1):9-12.

2. Epelman M, Dinan D, Gee MS, Servaes S, Lee EY, Darge K. Müllerian duct and related anomalies in 
children and adolescents. Magn Reson Imaging Clin N Am. 2013;21(4):773-89.

3. Deutch TD, Abuhamad AZ. The role of 3dimensional ultrasonography and magnetic resonance imaging in the diagnosis of Muscle duct anomalies. J Ultrasound Med. 2008;27:413-23.

4. Morelli M, Venturella R, Mocciaro R, Lico D, Zullo F. An unusual extremely distant noncommunicating uterine horn with myoma and adenomyosis treated with laparoscopic hemihysterectomy. Case Reports Obstetrics Gynecol. 2013;2013.

5. American Fertility Society: classification of mullerian anomalies. Fertil Steril. 1988;49:944.

6. Grimbizis GF, Gordts S, Di Spiezio Sardo A, Brucker S, De Angelis C, Gergolet M, et al. The ESHRE/ESGE consensus on the classification of female genital tract congenital anomalies. Human Reprod. 2013;28(8)2032-44

7. Gardner GJ, Reidy-Lagunes D, Gehrig PA. Neuroendocrine tumors of the gynecologic tract: A Society of Gynecologic Oncology (SGO) clinical document. Gynecol Oncol. 2011;122(1):190-8.
8. Liatsikos SA, Tsikouras P, Souftas V, Ammari A, Prassopoulos P, Maroulis G, et al. Diagnosis and laparoscopic management of a rudimentary uterine horn in a teenage girl, presenting with haematometra and severe endometriosis: Our experience and review of literature. Minim Invasive Ther Allied Technol. 2010;19(4):241-7.

9. Vallerie AM, Breech LL. Update in Mullerian anomalies: diagnosis, management, and outcomes. Curr Opin Obstet Gynecol. 2010;22(5):381-7.

10. Johary J, Xue M, Xu B, Xu D, Aili A. Use of hysteroscope for vaginoscopy or hysteroscopy in adolescents for the diagnosis and therapeutic management of gynecologic disorders: A systematic review. J Pediat Adolesc Gynecol. 2015;28(1):29-37.

Cite this article as: Shah NH, Joshi AV, Mourya S. Endoscopy in the management of a rudimentary noncommunicating functional horn. Int J Reprod Contracept Obstet Gynecol 2019;8:783-6. 